\title{
Blocking interferon $\gamma$ reduces expression of chemokines CXCL9, CXCL10 and CXCL11 and decreases macrophage infiltration in ex vivo cultured arteries from patients with giant cell arteritis
}

\author{
Marc Corbera-Bellalta, ${ }^{1}$ Ester Planas-Rigol, ${ }^{1}$ Ester Lozano, ${ }^{1}$ Nekane Terrades-García, ${ }^{1}$ \\ Marco A Alba, ${ }^{1}$ Sergio Prieto-González, ${ }^{1}$ Ana García-Martínez, ${ }^{2}$ Robert Albero, ${ }^{3}$ \\ Anna Enjuanes, ${ }^{4}$ Georgina Espígol-Frigolé, ${ }^{1}$ José Hernández-Rodríguez, ${ }^{1}$ \\ Pascale Roux-Lombard, ${ }^{5}$ Walter G Ferlin, ${ }^{6}$ Jean-Michel Dayer, ${ }^{7}$ \\ Marie H Kosco-Vilbois, ${ }^{5}$ Maria C Cid ${ }^{1}$
}

\begin{abstract}
Handling editor Tore K Kvien
- Additional material is published online only. To view please visit the journal online (http://dx.doi.org/10.1136/ annrheumdis-2015-208371).

For numbered affiliations see end of article.
\end{abstract}

\section{Correspondence to}

Dr Maria C Cid, Department of Autoimmune Diseases, Hospital Clínic, Villarroel 170, Barcelona 08036, Spain; mccid@clinic.ub.es

Received 4 August 2015 Revised 26 October 2015 Accepted 6 November 2015 Published Online First 23 December 2015

\section{ABSTRACT}

Background Interferon $\gamma$ (IFN $\gamma$ ) is considered a seminal cytokine in the pathogenesis of giant cell arteritis (GCA), but its functional role has not been investigated. We explored changes in infiltrating cells and biomarkers elicited by blocking IFN $\gamma$ with a neutralising monoclonal antibody, A6, in temporal arteries from patients with GCA.

Methods Temporal arteries from 34 patients with GCA (positive histology) and 21 controls were cultured on 3D matrix (Matrigel) and exposed to $\mathrm{A} 6$ or recombinant IFN $\gamma$. Changes in gene/protein expression were measured by qRT-PCR/western blot or immunoassay. Changes in infiltrating cells were assessed by immunohistochemistry/immunofluorescence. Chemotaxis/ adhesion assays were performed with temporal arteryderived vascular smooth muscle cells (VSMCs) and peripheral blood mononuclear cells (PBMCs).

Results Blocking endogenous IFN $\gamma$ with $A 6$ abrogated STAT-1 phosphorylation in cultured GCA arteries. Furthermore, selective reduction in CXCL9, CXCL10 and CXCL11 chemokine expression was observed along with reduction in infiltrating CD68 macrophages. Adding IFN $\gamma$ elicited consistent opposite effects. IFN $\gamma$ induced CXCL9, CXCL10, CXCL11, CCL2 and intracellular adhesion molecule-1 expression by cultured VSMC, resulting in increased PBMC chemotaxis/adhesion. Spontaneous expression of chemokines was higher in VSMC isolated from GCA-involved arteries than in those obtained from controls. Incubation of IFN $\gamma$-treated control arteries with PBMC resulted in adhesion/infiltration by CD68 macrophages, which did not occur in untreated arteries. Conclusions Our ex vivo system suggests that IFN $\gamma$ may play an important role in the recruitment of macrophages in GCA by inducing production of specific chemokines and adhesion molecules. Vascular wall components (ie, VSMC) are mediators of these functions and may facilitate progression of inflammatory infiltrates through the vessel wall.

\section{INTRODUCTION}

Giant cell arteritis (GCA) is a chronic inflammatory disease targeting large and medium-sized arteries in aged individuals. ${ }^{1}$ In spite of the initial response to high-dose glucocorticoids (GCs), $40-60 \%$ of patients relapse when GCs are tapered and prolonged GC treatment results in significant side effects. $^{2}$

Search for new therapeutic options requires better understanding of pathogenesis. GCA has been classically considered a Th1-mediated disease based on the granulomatous nature of inflammatory lesions with the presence of giant cells. ${ }^{1}{ }^{3}$ Moreover, while transcripts of several cytokines (ie, interleukin (IL)-6, tumour necrosis factor- $\alpha$ (TNF $\alpha$ ) can be detected in unaffected temporal artery biopsies (TABs) ${ }^{4-7}$ IFN $\gamma$, the distinctive cytokine produced by Th1 lymphocytes, is selectively expressed in GCA lesions. ${ }^{4}$ 7-12 Recently, Th17-mediated mechanisms are also emerging as a relevant component of GCA pathogenesis. ${ }^{9-13}$

IFN $\gamma$ has important roles in innate and adaptive immunity. It is primarily expressed by Th1 and natural killer (NK) cells and also by plasmacytoid dendritic cells, B cells and macrophages. ${ }^{14}{ }^{15}$ IFN $\gamma$ signals by inducing dimerisation of its receptor chains, which, in turn, induces phosphorylation of JAK 1 and JAK 2, creating binding sites for STAT-1. ${ }^{14} 16 \quad 17$ STAT-1 phosphorylation results in STAT-1 dimerisation or formation of multimolecular complexes (ie, ISFG3 composed by STAT-1, STAT-2 and IRF9 molecules) subsequently inducing transcription of genes bearing gamma-activated sequences or interferon-stimulated responsive elements (ISREs), respectively, in their promoter regions. ${ }^{14} 1617$ Some of the STAT-1-induced target genes are themselves transcription factors (ie, IRFs), creating subsequent waves of inflammatory molecule expression. ${ }^{18}$ Adding complexity, IFN $\gamma$ may also induce STAT-3, particularly in conditions of STAT-1 paucity. ${ }^{19}$ IFN $\gamma$ promotes NK cell activity, macrophage activation, Th1 differentiation and expression of class I and class II major histocompatibility complex molecules on antigen-presenting cells. ${ }^{14-21}$ Based on these functions, IFN $\gamma$ is thought to have a major role in GCA. Its expression by adventitial infiltrates in early GCA lesions suggests a relevant role from the initial steps of vascular inflammation. ${ }^{112} 22$ 
To date, no mechanistic studies assessing the role of IFN $\gamma$ in the development of full-blown lesions in GCA have been performed. In this study, we explored functional roles of IFN $\gamma$ on GCA lesions by exposing cultured temporal artery sections from patients with GCA to a neutralising anti-human IFN $\gamma$ monoclonal antibody.

\section{PATIENTS AND METHODS \\ Patient samples}

TABs were performed to 55 patients with suspected GCA for diagnostic purposes. A $5-15 \mathrm{~mm}$ segment was saved for the present study. Thirty-four patients had histopathological features of GCA in their TAB. Thirteen of them had started GC treatment $3.6 \pm 3.2$ days before TAB. Twenty-one patients had no inflammatory infiltrates and served as controls. Clinical data of GCA patients and final diagnosis in control patients are disclosed in online supplementary tables S1 and S2, respectively.

\section{Neutralising, monoclonal antibody $\mathrm{A} 6$ against IFN $\gamma$}

A6 is a fully human monoclonal antibody generated in the laboratories of Novimmune (Geneva, Switzerland) from human immunoglobulin libraries using in vitro display technologies. A6 binds to human IFN $\gamma$ and neutralises its bioactivity.

\section{Temporal artery culture}

Temporal artery sections from patients with GCA and controls were embedded in Matrigel to ensure prolonged survival, cultured ex vivo as described ${ }^{7}$ with or without A6 antibody $(10 \mu \mathrm{g} /$ $\mathrm{mL}$ ), recombinant IFN $\gamma$ at $100 \mathrm{ng} / \mathrm{mL}$ (R\&D Systems, Minneapolis, Minnesota, USA), human non-immune immunoglobulin IgG1 at $10 \mu \mathrm{g} / \mathrm{mL}$ (Sigma, Ayrshire, UK) as a negative control or dexamethasone $(0.5 \mu \mathrm{g} / \mathrm{mL}$, Sigma). Each condition was tested in 3-4 replicate wells. Biopsies were frozen in TRIzol reagent (Life Technologies) for RNA extraction or in radioimmunoprecipitation assay buffer with protease and phosphatase inhibitors for western blot studies.

\section{Cell culture}

Vascular smooth muscle cells (VSMCs) were isolated from TABs as previously described ${ }^{22}$ and used after 3-8 doubling passages. Peripheral blood mononuclear cells (PBMCs) were obtained from whole blood of healthy donors using Lymphoprep (Axis-Shield, Oslo, Norway) (see culture details in online supplementary methods).

In specific experiments, VSMCs were seeded in 12-well plates and cultured alone or with $0.5 \times 10^{6} \mathrm{PBMC} /$ well. At the end of the co-culture period, PBMCs were isolated from supernatants by centrifugation. The underlying VSMCs were separately recovered after gentle treatment with EDTA (Versene, Life Technologies) to remove adherent PBMC.

\section{Gene expression analysis}

Total RNA was obtained from cultured arteries or cells and cDNA was obtained by reverse-transcription (see online supplementary methods). Specific pre-developed TaqMan probes from Applied Biosystems (TaqMan Gene Expression Assays) (see online supplementary table S3) were used for PCR amplification. Fluorescence was detected with ABI PRISM 7900 Hardware and results were analysed with the Sequence Detection Software V.2.3 (Applied Biosystems). Gene expression was normalised to the expression of the endogenous control GUSb using comparative $\Delta$ Ct method. ${ }^{5-7} 11$ mRNA concentration was expressed in relative units with respect to GUSb expression.

\section{Chemokine secretion}

CXCL9, CXCL10 and CXCL11 concentrations in supernatants were measured by immunoassay using Quantikine (R\&D Systems).

\section{STAT-1 and STAT-3 phosphorylation in cultured arteries}

Lysates were obtained from cultured artery sections or VSMC and phospho-STAT-1/total STAT-1 and phosho-STAT-3/total STAT-3 were assessed by western blot (see online supplementary methods).

\section{Immunohistochemistry and immunofluorescence staining}

Detailed immunostaining of cultured temporal artery sections or VSMC, as well as primary and secondary antibodies used, are depicted in online supplementary methods.

\section{Chemotaxis assay}

PBMC chemotaxis was assessed using Boyden chambers with $5 \mu \mathrm{m}$ pore polycarbonate filters (see specific details in online supplementary methods).

\section{Cell adhesion assays}

VSMCs were grown to confluence in 96-well plates and stimulated with recombinant IFN $\gamma$. After $24 \mathrm{~h} 7.5 \times 10^{4}$ PBMCs per well were added and incubated at $37^{\circ} \mathrm{C}$ for $30 \mathrm{~min}$. Wells were gently rinsed with phosphate-buffered saline and cells were fixed and stained with $0.2 \%$ crystal violet in $20 \%$ methanol for $10 \mathrm{~min}$. Plates were extensively washed and crystal violet was solubilised with $1 \%$ sodium dodecyl sulfate $(50 \mu \mathrm{L} /$ well $)$. Optical density was assessed by spectrophotometry at $560 \mathrm{~nm}$ wavelength.

\section{Statistical analysis}

Student's t test, when applicable, or Mann-Whitney test was applied for independent or paired samples for statistical analysis using SPSS software, PASW V.18.0.

\section{RESULTS}

Clone A6, a neutralising human monoclonal antibody against IFN $\gamma$, recognises IFN $\gamma$ in GCA lesions and interferes with IFN $\gamma$-mediated signalling

Since A6 was screened and selected by its potential to neutralise IFN $\gamma$ in vitro, we assessed its ability to bind IFN $\gamma$ expressed in GCA lesions. As shown in figure 1, biotinylated A6 antibody immunostained GCA-involved temporal artery sections, whereas immunostaining with biotinylated human $\operatorname{IgG1}$ was negative. Moreover, immunostaining of non-inflamed temporal artery sections from a control individual was negative according to the absence of IFN $\gamma$ expression in normal arteries. ${ }^{4} 7$

Temporal artery culture in 3-D matrix has been shown to be a suitable model to test the effects of easily diffusing molecules such as dexamethasone. ${ }^{7}$ However, it is not known whether complex molecules such as monoclonal antibodies are able to elicit biological responses in this system. To test this point, we investigated whether A6 was able to interfere with IFN $\gamma$-mediated signalling in cultured arteries by exploring the phosphorylation status of the transcription factors STAT-1 and STAT-3. As shown in figure 1E, F, normal arteries in culture had a remarkable constitutive expression and phosphorylation of STAT-3 but not STAT-1. Involved GCA arteries in culture had increased expression and phosphorylation of STAT-1 and decreased expression and phosphorylation of STAT-3 compared with cultured normal arteries. A6 antibody decreased expression and phosphorylation of STAT-1, whereas STAT-3 expression/ 

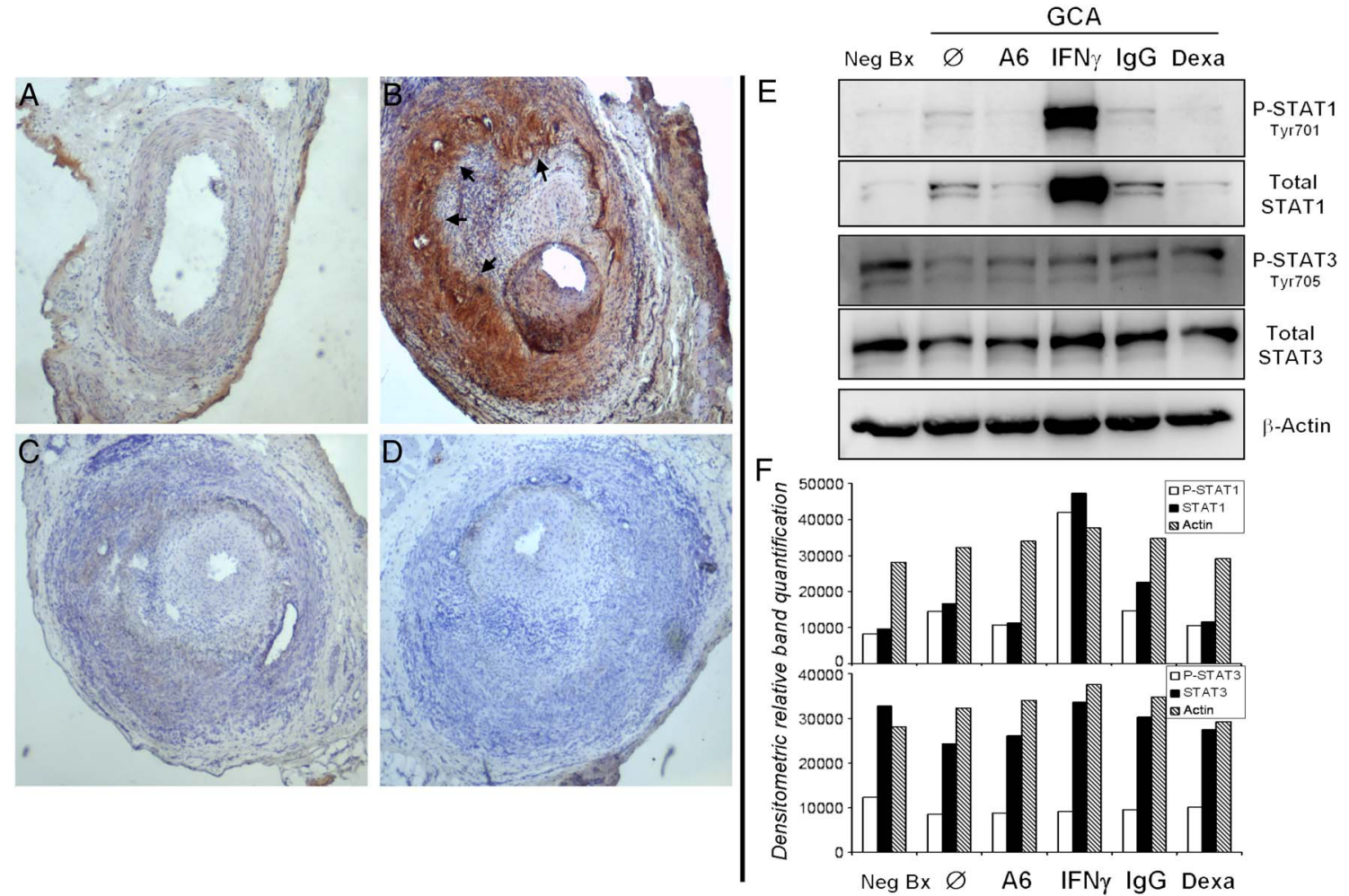

Figure 1 Interferon $\gamma$ (IFN $\gamma$ ) expression in arteries with giant cell arteritis (GCA) and the effects of IFN $\gamma$ on cultured temporal arteries from patients with GCA. (A-D) Immunostaining with A6 or control IgG1 on normal temporal arteries or GCA-involved arteries. (A) Histologically negative temporal artery from a control individual incubated with biotinylated A6 (negative control). (B) GCA-involved artery incubated with biotinylated A6 antibody (brown staining reflects IFN $\gamma$ expression). (C) A GCA-involved artery incubated with biotinylated non-immune human IgG1 (isotype control). (D) A GCA-involved artery incubated with the detection system reagents but no A6 (negative control). (E) Western blot performed to assess phosphorylated or total STAT-1 and STAT-3 in protein extracts of a cultured histologically negative biopsy (Neg Bx) and a cultured GCA-involved biopsy (GCA) untreated (Ø), exposed to A6 (10 $\mu \mathrm{g} / \mathrm{mL})$, IFN $\gamma(100 \mathrm{ng} / \mathrm{mL})$, human IgG1 (IgG; $10 \mu \mathrm{g} / \mathrm{mL}$ ) or dexamethasone (Dexa; $0.5 \mu \mathrm{g} / \mathrm{mL})$ for 5 days. The experiment was repeated twice with consistent results and a representative blot is shown. $\beta$-Actin was used as a control for loading. (F) Densitometric analysis of bands obtained in western blot experiments is exemplified in (E).

phosphorylation was not substantially affected. Treatment with recombinant IFN $\gamma$ strongly increased expression and phosphorylation of STAT-1.

\section{Neutralising endogenous IFN $\gamma$ production selectively downregulates CXCL9, CXCL10, CXCL11 chemokines and STAT-1 expression in cultured GCA arteries: adding exogenous IFN $\gamma$ elicits opposite effects}

We investigated the effects of neutralising IFN $\gamma$ with $\mathrm{A} 6$ on the expression of a variety of candidate molecules relevant to the pathogenesis of vascular inflammation and remodelling in GCA. ${ }^{3} 5^{11} 22-30$ Molecules investigated included transcription factors involved in T-cell functional differentiation, proinflammatory cytokines, chemokines/chemokine receptors, adhesion molecules, growth factors, metalloproteinases and their natural inhibitors, and extracellular matrix proteins (table 1 and figure 2). Since the temporal artery culture conveys by itself a downregulation of IFN $\gamma$ expression with respect to the original fresh arteries, which may have minimised these results, ${ }^{7}$ we sought to confirm the potential effects of IFN $\gamma$ revealed by inhibition with A6 antibody by treating cultured GCA arteries with recombinant IFN $\gamma$.

Among the molecules tested, neutralising endogenous IFN $\gamma$ with A6 mainly downregulated STAT-1 and chemokine CXCL9, CXCL10 and CXCL11 mRNAs (figure 2A). As shown in figure $2 \mathrm{~B}$, exposure of cultured GCA arteries to IFN $\gamma$ elicited the expected opposite effects and induced strong expression of
STAT-1 and chemokines CXCL9, CXCL10 and CXCL11 (figure 2B). CXCL9 and CXCL10 concentrations in the supernatant fluid were also reduced upon A6 antibody treatment and increased under exposure to recombinant IFN $\gamma$ (figure 2C). Concentrations of CXCL11 were around the detection level and were not substantially modified by A6 antibody or recombinant IFN $\gamma$, suggesting that CXCL11 is not secreted or is retained in the extracellular matrix.

Table 1 shows the effect of blocking IFN $\gamma$ with A6, as well as the effect of adding recombinant IFN $\gamma$ on the additional molecules tested. Neutralising IFN $\gamma$ with A6 tended to decrease HLA-DRA, TBX21, NOS-2, TNF $\alpha$, IL-6, CCL2, CXCR3, intracellular adhesion molecule-1 (ICAM-1) and platelet-derived growth factor A mRNAs and, consistently, these tended to increase upon exposure to recombinant IFN $\gamma$. However, with the exception of TNF $\alpha$, differences were not statistically significant, possibly due to the relatively low number of specimens analysed and the wide individual variability in expression of inflammatory products. Dexamethasone was able to markedly downregulate additional relevant molecules not influenced by A6 (table 1).

\section{VSMCs contribute to chemokine production induced by IFN $\gamma$}

Most of the effects of IFN $\gamma$ have been investigated in T cells, monocytes and endothelial cells. To mimic vascular inflammatory infiltrates, we co-cultured PBMC from healthy donors with human temporal artery-derived VSMC, the main component of the arterial wall. Co-culture induced a variety of chemokines 
Table 1 Mean fold change in mRNA of selected representative genes related to $T$ helper functional differentiation, inflammation and vascular remodelling in cultured temporal arteries from 34 patients with GCA and 21 controls subjected to different treatments (control IgG1, A6, recombinant IFN $\gamma$ or dexamethasone)

\begin{tabular}{|c|c|c|c|c|}
\hline Fold increase & GCA/control & Clone A6/lgG1 & $\begin{array}{l}\text { GCA biopsies } \\
\text { IFN } \gamma / \text { untreated }\end{array}$ & $\begin{array}{l}\text { Dexa/ } \\
\text { untreated }\end{array}$ \\
\hline \multicolumn{5}{|c|}{ Transcription factors } \\
\hline TBX21 & $3.1154^{*}$ & 0.7133 & $2.7776^{*}$ & 0.9522 \\
\hline GATA3 & $1.7611^{*}$ & 1.1780 & 1.3536 & 0.7716 \\
\hline RORC & $3.6482^{*}$ & 0.8558 & 1.3571 & $0.8380^{*}$ \\
\hline STAT-3 & 0.5913 & 0.9232 & 1.6143 & 1.0565 \\
\hline \multicolumn{5}{|c|}{ Proinflammatory molecules } \\
\hline \multicolumn{5}{|c|}{ Cytokines } \\
\hline IL-1 $\beta$ & $3.6162^{*}$ & 0.9041 & 1.1481 & 0.0342 \\
\hline TNF $\alpha$ & $1.6621^{*}$ & $0.7561^{*}$ & $2.7333^{*}$ & $0.3047^{*}$ \\
\hline IL-6 & 1.4685 & 0.7026 & 1.5621 & $0.0757^{*}$ \\
\hline $\mathrm{IFN} \gamma$ & $15.0840^{*}$ & 0.9119 & 0.6848 & $0.3869^{*}$ \\
\hline IL17A & $103.5418^{*}$ & 1.4793 & 0.5557 & $0.0279^{*}$ \\
\hline \multicolumn{5}{|l|}{ Chemokines } \\
\hline CCL2 & 1.6839 & 0.8950 & 1.2292 & $0.3424^{*}$ \\
\hline $\mathrm{CCL3}$ & $6.3415^{*}$ & 0.9815 & 0.4381 & $0.2125^{*}$ \\
\hline CCL4 & $13.9455^{*}$ & 1.0598 & 0.1611 & 0.2058 \\
\hline CCL5 & $4.8446^{*}$ & 1.2153 & 1.3709 & 0.6600 \\
\hline CXCL8 & 1.3023 & 0.9805 & 0.9512 & $0.0748^{*}$ \\
\hline \multicolumn{5}{|c|}{ Chemokine receptors } \\
\hline CCR2 & $6.9054^{*}$ & 1.3463 & 2.6116 & 0.5746 \\
\hline CXCR3 & $10.0717^{*}$ & 0.6640 & $2.1125^{*}$ & $\begin{array}{l}\text { Not } \\
\text { done }\end{array}$ \\
\hline \multicolumn{5}{|c|}{ Adhesion molecules } \\
\hline ICAM-1 & 1.7275 & 0.8225 & 2.0204 & 0.1137 \\
\hline VCAM-1 & 0.7031 & 0.9611 & 1.6861 & 0.0787 \\
\hline \multicolumn{5}{|l|}{ Other } \\
\hline HLADRA & $3.8304^{*}$ & 0.7373 & $3.0312^{*}$ & 0.8810 \\
\hline NOS-2 & 1.7010 & 0.2443 & 2.7067 & 1.7251 \\
\hline \multicolumn{5}{|c|}{ Vascular remodelling-related molecules } \\
\hline \multicolumn{5}{|l|}{ Growth factors } \\
\hline PDGFA & $0.4752^{*}$ & 0.7690 & 1.6640 & 0.4331 \\
\hline PDGFB & 0.6820 & 0.8081 & 1.0921 & 0.6338 \\
\hline TGF $\beta$ & $0.6106^{*}$ & 1.0119 & 1.2298 & 0.5117 \\
\hline \multicolumn{5}{|c|}{ Extracellular matrix proteins } \\
\hline FN1 & 0.8757 & 1.0473 & Not done & 2.3182 \\
\hline COL1 & 1.9086 & 0.9953 & Not done & 0.9594 \\
\hline COL3 & 0.9037 & 0.8602 & Not done & 1.0790 \\
\hline \multicolumn{5}{|c|}{ Metalloproteases } \\
\hline MMP-2 & $0.5738^{*}$ & 0.9101 & 0.5082 & 0.5827 \\
\hline MMP-9 & $2.3692^{*}$ & 0.8468 & 0.8204 & $0.0708^{*}$ \\
\hline \multicolumn{5}{|l|}{ MMP inhibitors } \\
\hline TIMP1 & $1.8323^{*}$ & 0.9844 & 1.0956 & $0.3405^{*}$ \\
\hline TIMP2 & $0.5663^{*}$ & 0.9815 & 0.9614 & 0.7737 \\
\hline
\end{tabular}

Number of specimens analysed: negative biopsies: 21; untreated GCA: 29; GCA treated with A6: 21; GCA treated with IgG1: 18; GCA treated with IFN $\gamma$ : 9; GCA treated with dexamethasone: 11 .

Bold values indicate consistent opposite results achieved by blocking IFN $\gamma$ with $\mathrm{A} 6$ or by adding recombinant IFN $\gamma$.

${ }^{*} \mathrm{p}<0.05$.

Clone A6, anti-human IFN $\gamma$ monoclonal antibody; GCA, giant cell arteritis; IgG1, isotype-matched control immunoglobulin; ICAM, intracellular adhesion molecule; IFN $\gamma$, recombinant interferon $\gamma$; MMP, matrix metalloproteinases; PDGF, platelet-derived growth factor. not only in PBMC but also in VSMC, indicating that VSMCs are an active source of chemokines in an inflammatory microenvironment (figure 3A). IFN $\gamma$ was produced and secreted by PBMC, basally and in co-culture (see online supplementary figure S1). In accordance with the previous results, neutralising IFN $\gamma$ with A6 strongly and selectively inhibited CXCL9, CXCL10 and CXCL11 chemokine expression by all cell types (figure 3A). A slight, non-significant, reduction in STAT-1 and adhesion molecule ICAM-1 was observed. No effects of A6 were observed on the expression of STAT-3, VCAM-1 or other chemokines tested in this multicellular system (figure $3 \mathrm{~A}$ and online supplementary figure S2).

To confirm that VSMC are an important source of chemokines upon IFN $\gamma$ influence, we exposed human temporal arteryderived VSMC to IFN $\gamma$, which elicited a remarkable increase in STAT-1 (figure 3B). An induction of CXCL9, CXCL10 and CXCL11 and upregulation of constitutive CCL2 was obtained, whereas expression of other chemokines related to Th1 responses (ie, CCL3, CCL4 or CCL5) or CXCL8 was not significantly induced (figure 3B). Promoter analysis (4 kb upstream and $1 \mathrm{~kb}$ downstream of the transcription initiating sequence) of chemokine genes was performed using Chip Bioinformatics Mapper (http://snpper.chip.org/mapper/mapper-main). ${ }^{31}$ The promoters of CXCL9, 10, and 11 as well as CCL2 shared ISRE sequences, whereas the remaining chemokines tested did not, supporting the exquisite sensitivity of these cytokines to IFN $\gamma$ exposure. However, although IFN $\gamma$ significantly upregulated constitutive CCL2 expression by cultured VSMC, A6 failed to downregulate CCL2 in multicellular systems such as PBMC/ VSMC co-culture or whole GCA arteries where other inducers may be present (table 1 and figure 3A).

As previously demonstrated in other settings, ${ }^{18} 3233$ IFN $\gamma$ also upregulated STAT-1 and adhesion molecule ICAM-1 expression by cultured VSMC and induced a slight expression of VCAM-1 and STAT-3 (figure 3B).

We next cultured temporal artery-derived VSMC from 8 patients and 11 controls and investigated chemokine production at passage zero to avoid phenotypic changes induced by prolonged culture. As shown in figure 3C, patient-derived VSMC conserved IFN $\gamma$ signature and expressed significantly higher mRNA concentrations of IFN $\gamma$-induced chemokine CXCL9 and a tendency to increased expression of CXCL10 and CCL2 than VSMC derived from control individuals. Higher mRNA concentrations of other chemokines not clearly influenced by IFN $\gamma$ in our experiments, particularly CCL4, were also observed. This may indicate VSMC exposure to stimuli other than IFN $\gamma$ or to second-wave IFN $\gamma$-induced mediators in the complex multicellular and multimolecular microenvironment existing in GCA lesions.

\section{Functional relevance of chemokine and adhesion molecule expression by VSMC}

Treatment of cultured temporal artery-derived VSMC with IFN $\gamma$ resulted in an increase in adhesion to PBMC (figure 4A).

The effect of IFN $\gamma$ on ICAM-1 expression by VSMC was confirmed in GCA lesions. VSMC expressed ICAM-1 in cultured GCA arteries, particularly in the vicinity of inflammatory infiltrates. ICAM-1 expression was reduced in sections treated with A6 antibody and increased in sections treated with IFN $\gamma$ (figure 4B). As already described, ${ }^{25}$ ICAM-1 expression was also observed in vasa vasorum endothelial cells and inflammatory cells (figure 4B). 
A
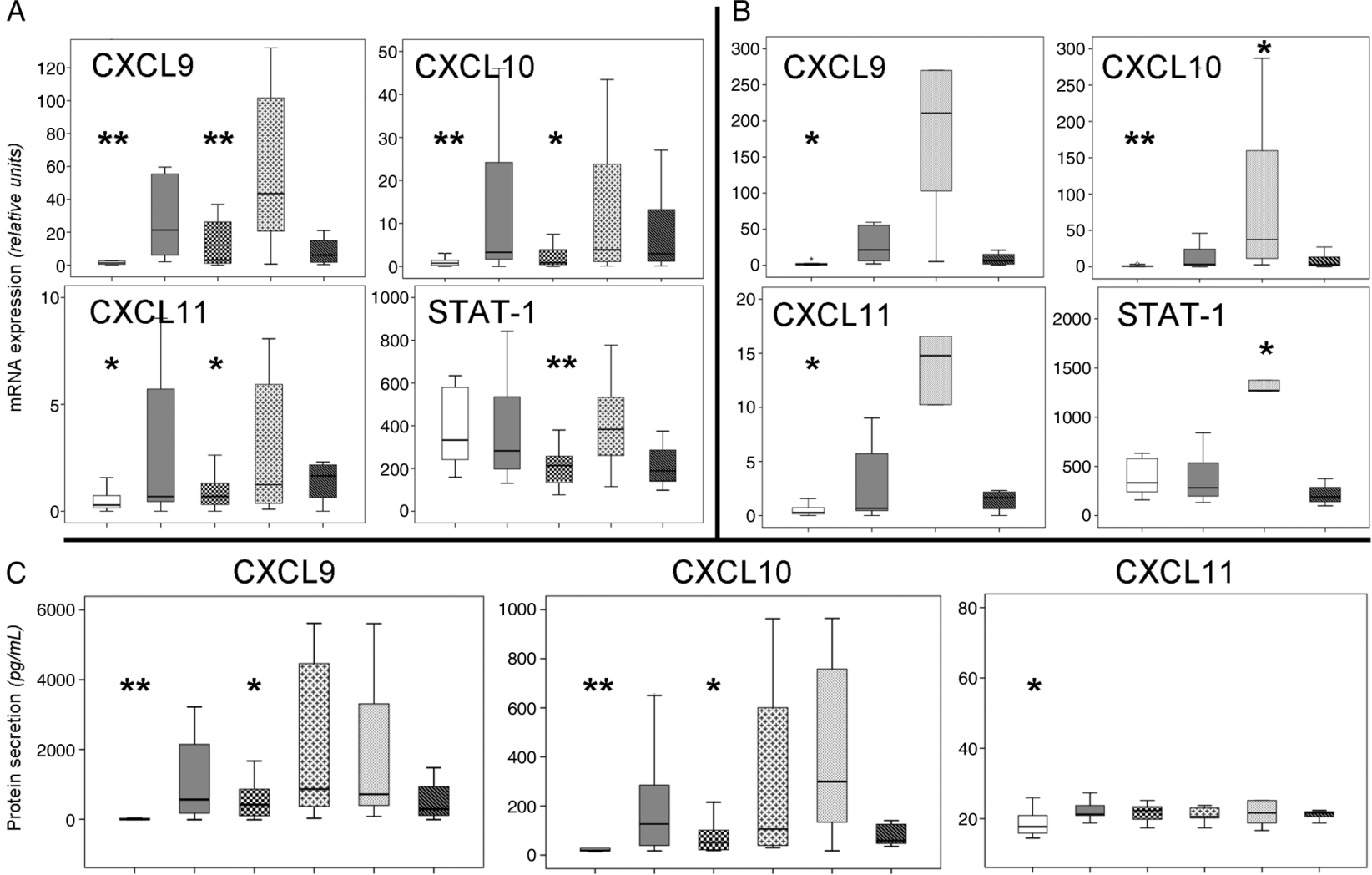

Negative biopsy

Untreated

CloneA6

IgG

IFN $\gamma$

Dexa

Figure 2 Changes in gene expression and protein secretion induced by blocking interferon $\gamma$ (IFN $\gamma$ ) with A6 or adding additional IFN $\gamma$ on cultured giant cell arteritis (GCA) biopsies. (A) mRNA concentrations (relative units) of CXCL9, CXCL10, CXCL11 and STAT-1 in cultured control arteries (negative biopsy) versus cultured GCA-involved arteries untreated or exposed to A6, human IgG1, or dexamethasone (Dexa) at the same concentrations as in figure 1. Statistical comparisons was performed between histologically negative and GCA-involved arteries and between IgG1-treated and A6-treated GCA involved arteries. ${ }^{*} p<0.05 ;{ }^{* *} p<0.005$. Notice that the $Y$ scale is different for each molecule. (B) mRNA concentrations (relative units) of CXCL9, CXCL10, CXCL11 and STAT-1 in cultured histologically negative arteries (negative biopsy) versus GCA-involved arteries untreated, or exposed to IFN $\gamma$ or dexamethasone (Dexa) at the same concentrations as in figure 1 in a different set of experiments. Statistical comparison was performed between histologically negative and GCA-involved arteries and between GCA arteries untreated or treated with recombinant IFN $\gamma$. ${ }^{*} p<0.05$; ${ }^{*} p<0.005$. Notice that the $Y$ scale is different for each molecule. (C) CXCL9, CXCL10 and CXCL11 concentrations ( $\mathrm{pg} / \mathrm{mL}$ ) in the supernatants of cultured normal arteries and GCA-affected arteries untreated or exposed to A6, human IgG1, IFN $\gamma$ or Dexa at the same concentrations as in figure 1. Statistical comparison was performed between histologically negative and GCA-involved arteries and between IgG1-treated and A6-treated GCA involved arteries. ${ }^{*} p<0.05 ;{ }^{* *} p<0.005$.

Chemokine-rich supernatant of VSMC exposed to IFN $\gamma$ stimulated PBMC chemotaxis in Boyden chambers (figure 4C), and this increase was abrogated by an antagonist of CXCR3, chemokine receptor common to CCL9, CXCL10 and CXCL11.

\section{Effects of IFN $\gamma$ neutralisation on infiltrating mononuclear} cells in cultured temporal arteries from patients with GCA The above findings suggest an important role for IFN $\gamma$ in the initial recruitment of inflammatory cells in temporal arteries from patients with GCA and the participation of VSMC, the major component of normal arteries in this process. To confirm this hypothesis, normal temporal arteries were exposed to recombinant IFN $\gamma$ and induction of CXCL9, CXCL10 and CXCL11 was confirmed (figure 5A). Incubation of IFN $\gamma$-treated normal arteries with PBMC from healthy donors resulted in infiltration of the artery wall by CD68 macrophages, which formed aggregates resembling giant cells (figure 5B). No CD3-positive cells penetrated the artery walls.
We next exposed cultured temporal arteries from patients with GCA to A6 and explored changes in the number of infiltrating $\mathrm{T}$ cells $(\mathrm{CD} 3)$ and macrophages (CD68). Blocking IFN $\gamma$ did not decrease the number of $\mathrm{T}$ cells (data not shown) but reduced the number of CD68-expressing cells and abrogated the presence of giant cells (figures 5C, D).

\section{DISCUSSION}

In this study, the first attempt to investigate the functional role of IFN $\gamma$ in GCA, blocking endogenous IFN $\gamma$ with a neutralising anti-IFN $\gamma$ antibody, led to a significant reduction of STAT-1 and chemokine CXCL9, CXCL10 and CXCL11 expression in ex vivo cultured GCA arteries. Moreover, neutralising IFN $\gamma$ resulted in decreased infiltration by CD68-expressing macrophages and reduced expression of $\mathrm{TNF} \alpha$ along with a nonsignificant trend to decrease inflammatory molecules typical of a proinflammatory (M1-like) phenotype (HLA-DRA and inducible nitric oxide synthase). ${ }^{20}$ These molecules, previously known to be expressed in GCA, are modulated by IFN $\gamma$ in other 

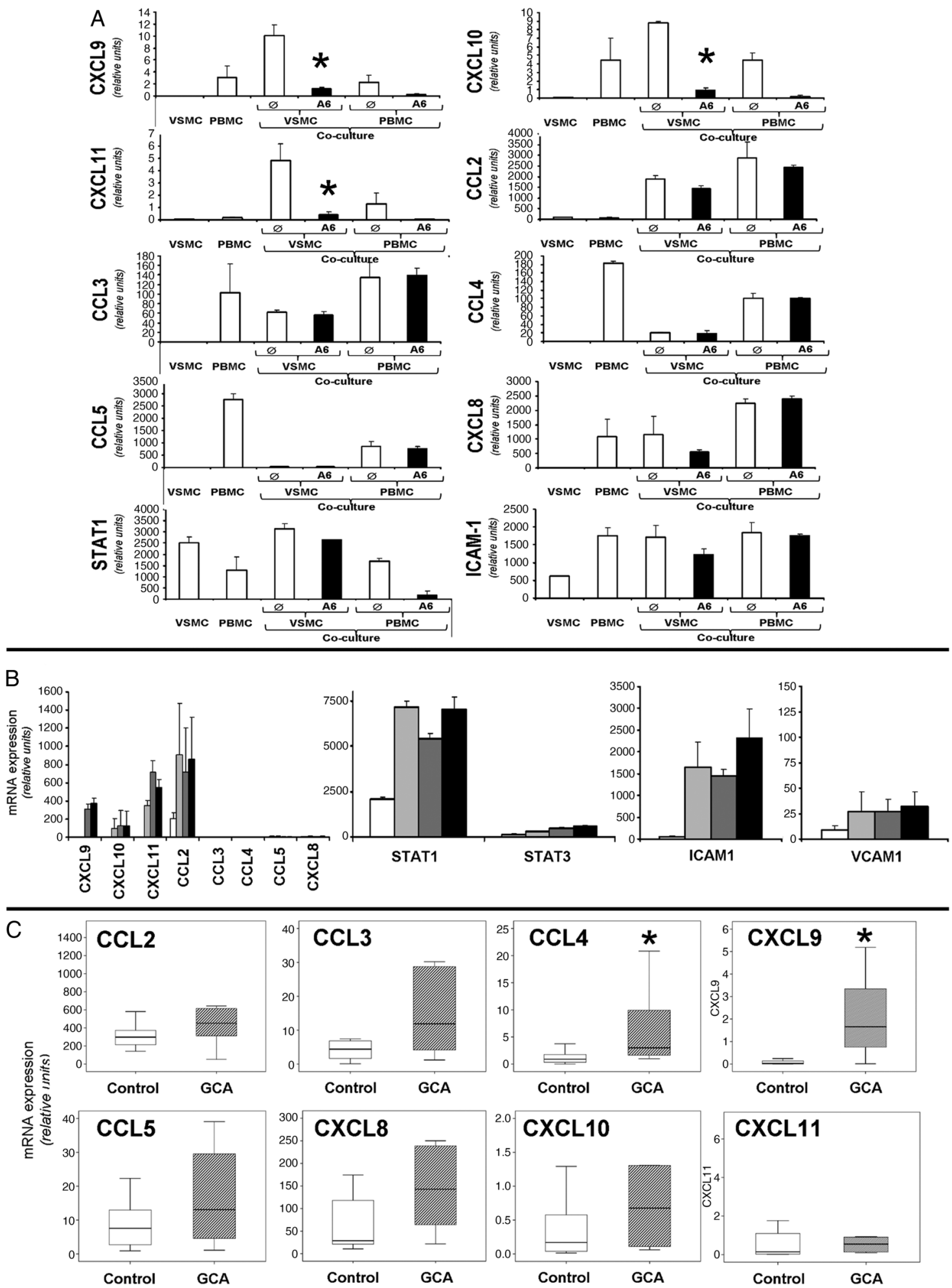

Figure 3 Effect of blocking the spontaneous interferon $\gamma$ (IFN $\gamma$ ) production by co-cultured vascular smooth muscle cells (VSMCS) and peripheral blood mononuclear cells (PBMCs) on chemokine expression and effect of adding IFN $\gamma$ on chemokine expression by temporal artery-derived VSMC. (A) VSMCs from normal temporal arteries were incubated alone or with PBMC (healthy donor) per well for $24 \mathrm{~h}$. PBMCs were also cultured alone as a control. Cells were cultured with (A6) (filled bars) or without (Ø) (empty bars) the anti-IFN $\gamma \mathrm{mAb}$ A6 (10 $\mu \mathrm{g} / \mathrm{mL})$. After co-culture, PBMCs (adherent and non-adherent) were separated from VSMC. RNA was extracted from each individualized cell type: PBMC cultured alone, VSMC cultured alone, co-cultured PBMC (adherent and non-adherent) and co-cultured VSMC, and mRNA levels of various chemokines was determined. Notice that the $Y$ scale is different for each molecule. The experiment was repeated three times with consistent results. *Significant reduction by A6 $p<0.05$ (B) Cultured VSMCs obtained from histologically normal temporal arteries were exposed to increasing concentrations of recombinant IFN $\gamma(0-20-50-100 \mathrm{ng} / \mathrm{mL})$ for $24 \mathrm{~h}$ and expression of transcription factors STAT-1 and STAT-3, chemokines and adhesion molecules intracellular adhesion molecule (ICAM)-1 and vascular adhesion molecule (VCAM)-1 was assessed by real-time quantitative RT-PCR. All increases in expression of chemokines, ICAM-1, STAT-1 and VCAM-1 were statistically significant $(p<0.05)$ compared to baseline. Increase in STAT-3 was significant $(p<0.05)$ at the highest IFN $\gamma$ concentration. (C) Spontaneous chemokine mRNA expression (relative units) by primary cultures of VSMC obtained from 11 normal arteries (empty boxes) or giant cell arteritis (GCA)-involved arteries (filled boxes). ${ }^{*} p<0.05$. 

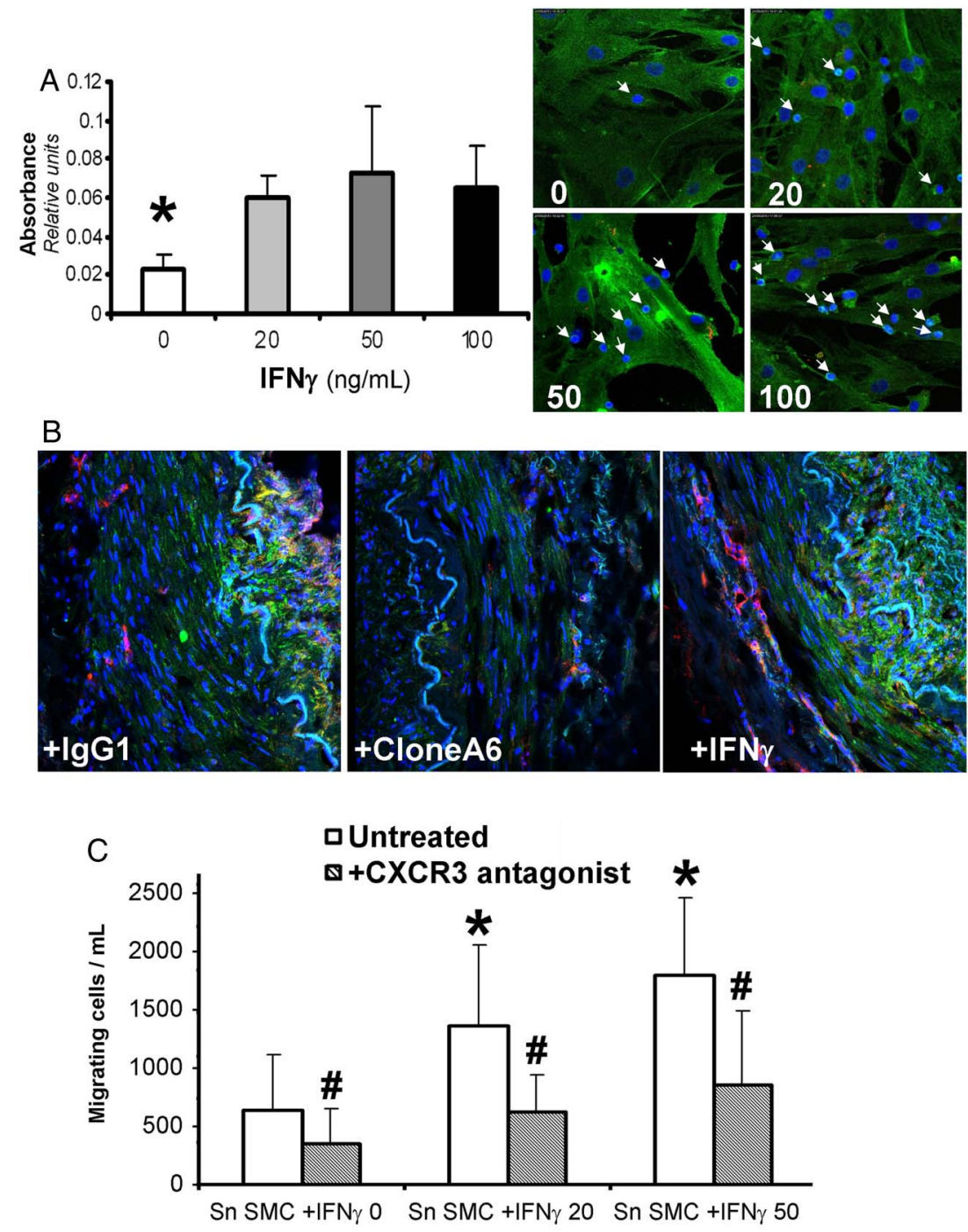

Figure 4 Changes in vascular smooth muscle cell (VSMCs) adhesiveness and chemoattraction to peripheral blood mononuclear cells (PBMCs) upon exposure to interferon $\gamma$ (IFN $\gamma$ ). (A) PBMC adhesion to VSMC obtained from histologically normal temporal arteries and exposed to increasing concentrations of IFN $\gamma$. VSMC cultured in 96-well plates were exposed to increasing concentrations of IFN $\gamma(0-20-50-100 \mathrm{ng} / \mathrm{mL}) \mathrm{for} 24 \mathrm{~h}$. PBMCs (75 000/well) were added and incubated for $1 \mathrm{~h}$, washed and stained with crystal violet. Bars represent absorbance of solubilised dye in VSMC incubated with PBMC after subtraction of absorbance obtained from VSMC alone. ${ }^{*} p<0.05$. In parallel confirmatory experiments, VSMCs were seeded in chamber slides (Nunc, Waltham, Massachusetts, USA), and VSMCs were immunostained with a mouse monoclonal anti-human alpha smooth muscle actin antibody (ab54723, Abcam) (green). Nuclei were stained with DAPI (blue). The size of PBMC nuclei (indicated by arrows) are smaller than those from VSMC and can be easily distinguished. (B) Expression of intracellular adhesion molecule (ICAM)-1 (green) and CD31 (red) in temporal arteries from a patient with giant cell arteritis (GCA) exposed to lgG1 $(10 \mu \mathrm{g} / \mathrm{mL})$, A6 $(10 \mu \mathrm{g} / \mathrm{mL})$ or IFN $\gamma(100 \mathrm{ng} / \mathrm{mL}) \mathrm{for} 5 \mathrm{days}$. Nuclei were stained with DAPI (blue). VSMCs (elongated cells) express ICAM -1, particularly in the vicinity of infiltrating mononuclear cells. Co-expression of CD31 and ICAM-1 (merged, yellow) is observed on endothelial cells from adventitial vasa vasorum and neovessels. ICAM-1 expression is clearly reduced by A6 antibody. (C) Chemotactic activity of PBMC to the supernatant of VSMC exposed to IFN $\gamma$. Supernatants from VSMC obtained from histologically normal arteries incubated with increasing concentrations IFN $\gamma(0-20-50 \mathrm{ng} / \mathrm{mL})$ for $24 \mathrm{~h}$ were used to assess the induction of PBMC chemotaxis in the presence or in the absence of the CXCR3 inhibitor 500486. Bars represent the number of cells $/ \mathrm{mL}$ that migrated to the lower chamber after $6 \mathrm{~h}$ incubation (mean \pm SD of three counts). ${ }^{*} \mathrm{p}<0.05$ (increase in migration at any IFN $\gamma$ concentration versus baseline). \#p $<0.05$ (inhibition by CXCR3 antagonist).

settings. 519202326 Treatment of GCA arteries with exogenous IFN $\gamma$ elicited opposite effects and tendencies, supporting the specificity of these findings.

Blocking IFN $\gamma$ in our system led to a highly selective inhibition of ISRE-containing chemokine genes CXCL 9, 10 and 11. Although IFN $\gamma$ also induced ISRE-dependent CCL2 in isolated VSMC, the effect of blocking IFN $\gamma$ on CCL2 expression in GCA arteries was not apparent probably due to the remarkable constitutive expression of CCL2 in aged temporal arteries and the presence of potential additional inducers. ${ }^{34}$ Since CXCL 9,
10 and 11 are powerful chemoattractants of mononuclear cells and these are able to interact with ICAM-1 expressing microvessels in inflamed arteries, our findings support a relevant role for IFN $\gamma$ in the development and perpetuation of inflammatory infiltrates.

Based on the potent known effects of IFN $\gamma$ on macrophages, and their predominance in GCA lesions, we expected that blocking IFN $\gamma$ would have higher impact in the expression of downstream macrophage inflammatory products such as HLA-DR, NOS-2 and monokines. ${ }^{20}$ In our model, IFN $\gamma$ 

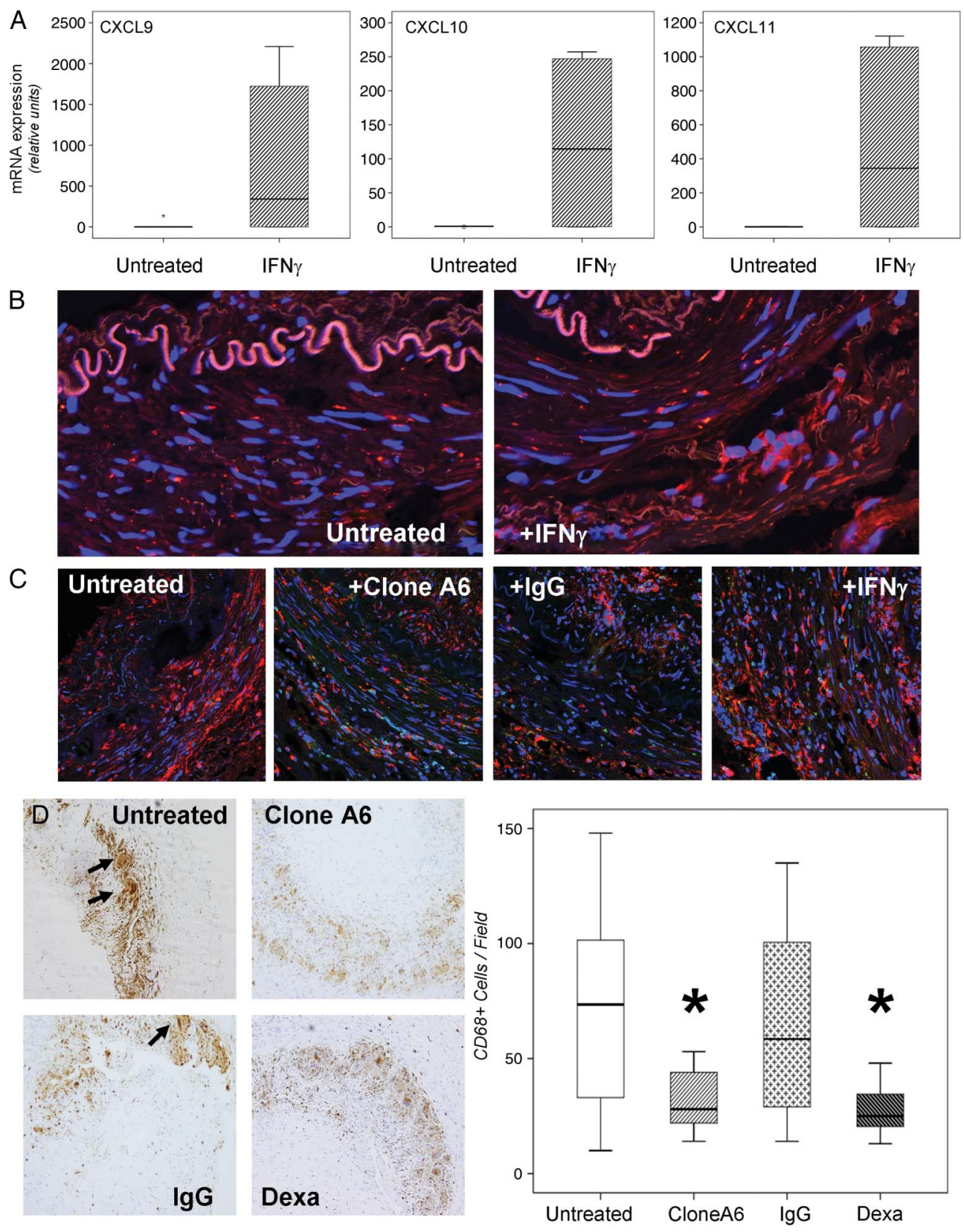

Figure 5 Effect of interferon $\gamma$ (IFN $\gamma$ ) on chemokine expression and macrophage infiltration of histologically normal temporal arteries and reduction of macrophage infiltration in giant cell arteritis (GCA)-involved arteries following IFN $\gamma$ blockade. (A) Histologically normal temporal arteries $(\mathrm{N}=6)$ were cultured on Matrigel with or without IFN $\gamma(100 \mathrm{ng} / \mathrm{mL})$ for 5 days and chemokine mRNA expression was assessed (relative units) by RT-PCR. (B) Histologically normal temporal arteries cultured in 24-well plates as above were incubated in medium alone or in medium containing IFN $\gamma(100 \mathrm{ng} / \mathrm{mL})$ for 4 days and were subsequently exposed to PBMC from a healthy donor $\left(0.25 \times 10^{6} /\right.$ well) for 5 days. Cryosections of the retrieved arteries were processed for immunofluorescence, sectioned and immunostained with an anti-CD68 mAb (red). Nuclei were stained with DAPI (blue). (C) GCA affected temporal arteries were cultured in medium alone or in medium containing A6 antibody $(10 \mu \mathrm{g} / \mathrm{mL})$, control $\mathrm{lgG1}(10 \mu \mathrm{g} / \mathrm{mL})$ or recombinant IFN $\gamma(100 \mathrm{ng} / \mathrm{mL})$ for 5 days, washed and processed for immunofluorescence and immunostained with anti-CD68 mAb as in (B). Nuclei were stained with DAPI (blue). (D) Cryosections of GCA-affected temporal arteries, cultured as in (C), were immunostained with an anti-CD68 mAb. Notice reduction in immunostained CD68 cells and disappearance of giant cells (arrows) following anti-IFN $\gamma$ or dexamethasone (Dexa) $(0.5 \mu \mathrm{g} / \mathrm{mL}$ ) treatment. Graph shows number of CD68+ cells/field (x100) in cultured GCA-involved temporal arteries untreated or exposed to A6, control IgG1 or dexamethasone (Dexa). Twelve fields/condition were assessed. ${ }^{*} \mathrm{p}<0.05$.

neutralisation slightly modified or did not modify at all a number of relevant proinflammatory molecules that were, indeed, suppressed by GC. This may be determined by concomitant activation of IFN $\gamma$-independent pathways. In this regard, neutralisation of IFN $\gamma$ did not substantially reduce expression and activation of STAT-3, which appears to be highly activated in normal arteries and in GCA lesions, in accordance with the remarkable production of IL-6 in normal and inflamed arteries. $^{4-6}$ Concomitant activation of STAT-3 and nuclear factor- $\mathrm{KB}$ may sustain expression of many inflammatory molecules in spite of IFN $\gamma$ blockade. ${ }^{35-37}$

Most of the studies investigating IFN $\gamma$ proinflammatory functions have explored its effects on macrophages and endothelial cells. $^{18} 33$ In vascular biology, the effects of IFN $\gamma$ have been 
essentially investigated in the setting of atherosclerosis and graft vasculopathy. ${ }^{38}{ }^{39}$ In these models, IFN $\gamma$ is expressed in lesions and production of IFN $\gamma$ induced chemokines have been attributed to endothelial cells and inflammatory cells and only occasionally related to myofibroblasts. ${ }^{38}$ In VSMC, the effects of IFN $\gamma$ have been mainly related to vascular remodelling and neointima formation. ${ }^{39}$ In recent years, it has become apparent that VSMC may acquire a strong proinflammatory phenotype in the appropriate context. ${ }^{40}{ }^{41}$ Our findings indicate that, in GCA, VSMC are also important targets for IFN $\gamma$, which renders them active producers of chemokines and adhesion molecules, especially ICAM-1. Consequently, VSMCs likely contribute to the progression of inflammatory infiltrates through the medial layer of the artery wall and to the development of full-blown granulomatous lesions in GCA.

GC, the cornerstone of current GCA treatment, rapidly downregulate the expression of a variety of inflammatory cytokines (ie, IL-1 $\beta, \mathrm{TNF} \alpha$, IL-6, IL-17), adhesion molecules (ie, ICAM-1) and matrix metalloproteinases (ie, MMP-9). ${ }^{7} 112728$ However, GC do not repress IFN $\gamma$ transcription. ${ }^{35}$ Although prolonged GC treatment eventually results in decreased IFN $\gamma$ expression by other mechanisms, ${ }^{11}{ }^{42-44}$ acute GC effects on IFN $\gamma$ expression in GCA lesions are less dramatic than that observed with other cytokines. ${ }^{7} 2735$ This has led to the hypothesis that incomplete suppression of IFN $\gamma$ accounts for GCA relapses during GC tapering or withdrawal, ${ }^{29}$ and IFN $\gamma$ has been considered a potential therapeutic target. ${ }^{29} 35$ However, our findings indicate that reducing STAT- 1 expression and activation by blocking IFN $\gamma$ may not be sufficient to abrogate inflammatory activity in full-blown GCA lesions, which may require blockade of multiple pathways. However, interfering with IFN $\gamma$ might be useful in preventing relapses, given the relevant role of IFN $\gamma$ in the recruitment of inflammatory cells since the very early inflammatory stages. ${ }^{11} 45$

In considering IFN $\gamma$ as a potential therapeutic target, it is important to consider that IFN $\gamma$ may have a protective role by limiting tissue injury ${ }^{16}{ }^{46}$ Blocking IFN $\gamma$ worsens, indeed, experimental arthritis by promoting Th17 differentiation and exacerbation of IL-17-mediated inflammatory responses. ${ }^{47}$ In addition, an infectious trigger of GCA has been postulated, although no causative agents have been consistently identified. ${ }^{48}$ In this regard, IFN $\gamma$-deficient mice infected with murine herpesvirus HV68 develop necrotising large-vessel vasculitis, supporting the wellknown role of IFN $\gamma$ in host defence against viruses but also suggesting a role in limiting vascular injury. ${ }^{46}{ }^{49}$ Moreover, in some experimental settings, but not in others, IFN $\gamma$ deficiency exacerbates aortic aneurysm development, which is one of the important delayed complications of GCA. ${ }^{50-56}$

Our study has several limitations. On the one hand, it explores functional activities of IFN $\gamma$ in a target organ isolated from a functional immune system and variations in chemokine and adhesion molecule expression could not result in effective changes in leucocyte recruitment. It is likely that, in vivo, inhibition of lymphocyte and monocyte recruitment and subsequent macrophage activation would result in greater impact on the generation of downstream inflammatory products. In addition, as mentioned, the culture itself downregulates IFN $\gamma$ expression, ${ }^{7}$ which may have minimised the effect of IFN $\gamma$ neutralisation in our model. GC treatment of some patients prior to the TAB may also have influenced results.

In spite of these limitations, our findings indicate an important role for IFN $\gamma$ in the recruitment and activation of macrophages, which may sustain and amplify subsequent waves of proinflammatory cascades in GCA. Moreover, our findings support the suitability of the temporal artery culture model to test functional activities not only of pharmacological agents or chemicals but also of complex molecules such as biological agents.

\section{Author affiliations}

${ }^{1}$ Vasculitis Research Unit, Department of Autoimmune Diseases, Hospital Clínic, University of Barcelona, Institut d'Investigacions Biomèdiques August Pi i Sunyer (IDIBAPS), Barcelona, Spain

${ }^{2}$ Department of Emergency Medicine, Hospital Clínic, University of Barcelona, Institut d'Investigacions Biomèdiques August Pi i Sunyer (IDIBAPS), Barcelona, Spain

${ }^{3}$ Hematopathology Section, Department of Anatomic Pathology, Hospital Clínic, University of Barcelona, Institut d'Investigacions Biomèdiques August Pi i Sunyer (IDIBAPS), Barcelona, Spain

${ }^{4}$ Genomics and Haematopathology Unit, Hospital Clínic, University of Barcelona, Institut d'Investigacions Biomèdiques August Pi i Sunyer (IDIBAPS), Barcelona, Spain ${ }^{5}$ Division of Immunology and Allergy, University Hospital and Medical School, University of Geneva, Geneva, Switzerland

${ }^{6}$ Novimmune, Geneva, Switzerland

${ }^{7}$ Medical School, University of Geneva, Geneva, Switzerland

Contributors MCC and MC-B designed the study. MHK-V and J-MD contributed important input to its design. MC-B, EP-R, EL and NT performed the experimental work. MAA, SP-G, AG-M, GE-F and JH-R contributed to clinical selection and contributed to the experimental work. RA and AE supervised in silico promoter regions studies. All authors evaluated and criticised the data and PR-L and MHK-V provided important contributions to their interpretation. MC-B and MCC wrote the manuscript. All authors read, made improvements and approved the final version.

Funding Supported by Ministerio de Economía y Competitividad (SAF 11/30073 and SAF 14/57708-R) and by Instituto de Salud Carlos III (PIE13/00033) and Fondo europeo de Desarrollo Regional (FEDER)

Competing interests MHK-V and WGF are full employees by Novimmune. MCC, $\mathrm{J}-\mathrm{HR}, \mathrm{GE}-\mathrm{F}$ and SP-G are currently participating in a clinical trial of tocilizumab (anti-IL-6R) in giant cell arteritis sponsored by Hoffmann-La Roche.

Patient consent Obtained.

Ethics approval Ethics committee of Hospital Clínic of Barcelona.

Provenance and peer review Not commissioned; externally peer reviewed.

\section{REFERENCES}

1 Salvarani C, Pipitone N, Versari A, et al. Clinical features of polymyalgia rheumatica and giant cell arteritis. Nat Rev Rheumatol 2012;8:509-21.

2 Alba MA, García-Martínez A, Prieto-González $S$, et al. Relapses in patients with giant cell arteritis: prevalence, characteristics, and associated clinical findings in a longitudinally followed cohort of 106 patients. Medicine 2014;93:194-201.

3 Cid MC, Font C, Coll-Vinent B, et al. Large vessel vasculitides. Curr Opin Rheumatol 1998;10:18-28

4 Weyand CM, Hicok KC, Hunder GG, et al. Tissue cytokine patterns in patients with polymyalgia rheumatica and giant cell arteritis. Ann Intern Med 1994;121:484-91.

5 Hernández-Rodríguez J, Segarra M, Vilardell C, et al. Tissue production of pro-inflammatory cytokines (IL-1beta, TNF alpha and IL-6) correlates with the intensity of the systemic inflammatory response and with corticosteroid requirements in giant-cell arteritis. Rheumatology (Oxford) 2004;43:294-301.

6 Hernández-Rodríguez J, Segarra M, Vilardell C, et al. Elevated production of interleukin- 6 is associated with a lower incidence of disease-related ischemic events in patients with giant-cell arteritis: angiogenic activity of interleukin- 6 as a potential protective mechanism. Circulation 2003;107:2428-34.

7 Corbera-Bellalta M, García-Martínez A, Lozano E, et al. Changes in biomarkers after therapeutic intervention in temporal arteries cultured in Matrigel: a new model for preclinical studies in giant-cell arteritis. Ann Rheum Dis 2014;73:616-23.

8 Ciccia F, Alessandro R, Rizzo A, et al. Expression of interleukin-32 in the inflamed arteries of patients with giant cell arteritis. Arthritis Rheum 2011;63:2097-104.

9 Deng J, Younge BR, Olshen RA, et al. Th17 and Th1 T-cell responses in giant cell arteritis. Circulation 2010;121:906-15.

10 Terrier B, Geri G, Chaara W, et al. Interleukin-21 modulates Th1 and Th17 responses in giant cell arteritis. Arthritis Rheum 2012;64:2001-11.

11 Visvanathan S, Rahman MU, Hoffman GS, et al. Tissue and serum markers of inflammation during the follow-up of patients with giant-cell arteritis-a prospective longitudinal study. Rheumatology (Oxford) 2011;50:2061-70.

12 Samson M, Audia S, Fraszczak J, et al. Th1 and Th17 lymphocytes expressing CD161 are implicated in giant cell arteritis and polymyalgia rheumatica pathogenesis. Arthritis Rheum 2012;64:3788-98.

13 Espígol-Frigolé G, Corbera-Bellalta M, Planas-Rigol E, et al. Increased IL-17A expression in temporal artery lesions is a predictor of sustained response to glucocorticoid treatment in patients with giant-cell arteritis. Ann Rheum Dis 2013;72:1481-7. 
14 Schroder K, Hertzog PJ, Ravasi T, et al. Interferon-gamma: an overview of signals, mechanisms and functions. J Leukoc Biol 2004;75:163-89.

15 Qiao Y, Giannopoulou EG, Chan CH, et al. Synergistic activation of inflammatory cytokine genes by interferon- $\gamma$-induced chromatin remodeling and toll-like receptor signaling. Immunity 2013;39:454-69.

16 Hu X, Ivashkiv LB. Cross-regulation of signaling pathways by interferon-gamma: implications for immune responses and autoimmune diseases. Immunity 2009:31:539-50.

17 Saha B, Jyothi Prasanna S, Chandrasekar B, et al. Gene modulation and immunoregulatory roles of interferon gamma. Cytokine 2010;50:1-14.

$18 \mathrm{Hu}$ X, Park-Min KH, Ho HH, et al. IFN-gamma-primed macrophages exhibit increased CCR2-dependent migration and altered IFN-gamma responses mediated by Stat1. J Immunol 2005;175:3637-47.

19 Qing Y, Stark GR. Alternative activation of STAT1 and STAT3 in response to interferon-gamma. J Biol Chem 2004;279:41679-85.

20 Murray PJ, Wynn TA. Protective and pathogenic functions of macrophage subsets. Nat Rev Immunol 2011:11:723-37.

21 Gough DJ, Levy DE, Johnstone RW, et al. IFN $\gamma$ signalling- does it mean JAK-STAT? Cytokine Growth Factor Rev 2008;19:383-94.

22 Lozano E, Segarra M, García-Martínez A, et al. Imatinib mesylate inhibits in vitro and ex vivo biological responses related to vascular occlusion in giant cell arteritis. Ann Rheum Dis 2008:67:1581-8.

23 Cid MC, Campo E, Ercilla G, et al. Immunohistochemical analysis of lymphoid and macrophage cell subsets and their immunologic activation markers in temporal arteritis. Influence of corticosteroid treatment. Arthritis Rheum 1989;32:884-93.

24 Cid MC, Hoffman MP, Hernández-Rodríguez J, et al. Association between increased CCL2 (MCP-1) expression in lesions and persistence of disease activity in giant-cell arteritis. Rheumatology (Oxford) 2006;45:1356-63.

25 Cid MC, Cebrián M, Font C, et al. Cell adhesion molecules in the development of inflammatory infiltrates in giant cell arteritis: inflammation-induced angiogenesis as the preferential site of leukocyte-endothelial cell interactions. Arthritis Rheum 2000;43:184-94

26 Weyand $C M$, Wagner AD, Björnsson J, et al. Correlation of the topographical arrangement and the functional pattern of tissue-infiltrating macrophages in giant cell arteritis. J Clin Invest 1996;98:1642-9.

27 Brack A, Rittner HL, Younge BR, et al. Glucocorticoid-mediated repression of cytokine gene transcription in human arteritis-SCID chimeras. J Clin Invest 1997;99:2842-50.

28 Segarra M, García-Martínez A, Sánchez M, et al. Gelatinase expression and proteolytic activity in giant-cell arteritis. Ann Rheum Dis 2007;66:1429-35.

29 Weyand CM, Goronzy JJ. Immune mechanisms in medium and large-vessel vasculitis. Nat Rev Rheumatol 2013:9:731-40.

30 Ly KH, Regent A, Tamby MC, et al. Pathogenesis of giant-cell arteritis: more than just an inflammatory condition?. Autoimmunity Rev 2010;9:635-45.

31 Marinescu VD, Kohane IS, Riva A. The MAPPER database: a multi-genome catalog of putative transcription factor binding sites. Nucleic Acids Res 2005;33:D91-7.

32 Braun M, Pietsch P, Felix SB, et al. Modulation of intercellular adhesion molecule-1 and vascular cell adhesion molecule-1 on human coronary smooth muscle cells by cytokines. J Mol Cell Cardiol 1995;27:2571-9.

33 Nourshargh S, Alon R. Leukocyte migration into inflamed tissues. Immunity 2014:41:694-707.

34 Wang M, Jiang L, Monticone RE, et al. Proinflammation: the key to arterial aging. Trends Endocrinol Metab 2014:25:72-9.

35 Weyand $\mathrm{CM}$, Kaiser $\mathrm{M}$, Yang $\mathrm{H}$, et al. Therapeutic effects of acetylsalicylic acid in giant cell arteritis. Arthritis Rheum 2002;46:457-66.

36 Shin WS, Hong YH, Peng HB, et al. Nitric oxide attenuates vascular smooth muscle cell activation by interferon-gamma. The role of constitutive NF-kappa B activity. J Biol Chem 1996;271:11317-24.
37 Kovacic JC, Gupta R, Lee AC, et al. Stat3-dependent acute Rantes production in vascular smooth muscle cells modulates inflammation following arterial injury in mice. J Clin Invest 2010;120:303-14.

38 Zhao DX, Hu Y, Miller GG, et al. Differential expression of the IFN-gamma-inducible CXCR3-binding chemokines, IFN-inducible protein 10, monokine induced by IFN, and IFN-inducible T cell alpha chemoattractant in human cardiac allografts: association with cardiac allograft vasculopathy and acute rejection. J Immunol 2002;169:1556-60.

39 Tellides G, Tereb DA, Kirkiles-Smith NC, et al. Interferon-gamma elicits arteriosclerosis in the absence of leukocytes. Nature 2000;403:207-11.

40 Tellides G, Pober JS. Inflammatory and immune responses in the arterial media. Circ Res 2015:116:312-22.

41 Libby $\mathrm{P}$, Hansson GK. Inflammation and immunity in diseases of the arterial tree: players and layers. Circ Res 2015;116:307-11.

42 Ogilvie RL, Sternjohn JR, Rattenbacher B, et al. Tristetraprolin mediates interferon-gamma mRNA decay. J Biol Chem 2009;284:11216-23.

43 Ishmael FT, Fang X, Galdiero MR, et al. Role of the RNA-binding protein tristetraprolin in glucocorticoid-mediated gene regulation. J Immunol 2008;180:8342-53.

44 Liberman AC, Refojo D, Druker J, et al. The activated glucocorticoid receptor inhibits the transcription factor T-bet by direct protein-protein interaction. FASEB J 2007;21:1177-88.

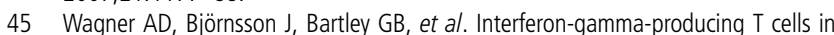
giant cell vasculitis represent a minority of tissue-infiltrating cells and are located distant from the site of pathology. Am J Pathol 1996;148:1925-33.

46 Kelchtermans H, Billiau A, Matthys P. How interferon-gamma keeps autoimmune diseases in check. Trends Immunol 2008;29:479-86.

47 Kelchtermans H, Schurgers E, Geboes L, et al. Effector mechanisms of interleukin-17 in collagen-induced arthritis in the absence of interferon-gamma and counteraction by interferon-gamma. Arthritis Res Ther 2009:11:R122.

48 Bhatt AS, Manzo VE, Pedamallu CS, et al. In search of a candidate pathogen for giant cell arteritis: sequencing-based characterization of the giant cell arteritis microbiome. Arthritis Rheumatol 2014;66:1939-44.

49 Weck KE, Dal Canto AJ, Gould JD, et al. Murine gamma-herpesvirus 68 causes severe large-vessel arteritis in mice lacking interferon-gamma responsiveness: a new model for virus-induced vascular disease. Nat Med 1997;3:1346-53.

50 Shimizu K, Shichiri M, Libby P, et al. Th2-predominant inflammation and blockade of IFN-gamma signaling induce aneurysms in allografted aortas. J Clin Invest 2004;114:300-8.

51 King VL, Lin AY, Kristo F, et al. Interferon-gamma and the interferon-inducible chemokine CXCL10 protect against aneurysm formation and rupture. Circulation 2009;119:426-35.

52 Tang PC, Yakimov AO, Teesdale MA, et al. Transmural inflammation by interferon-gamma-producing $T$ cells correlates with outward vascular remodeling and intimal expansion of ascending thoracic aortic aneurysms. FASEB $J$ 2005:19:1528-30.

53 García-Martínez A, Hernández-Rodríguez J, Arguis P, et al. Development of aortic aneurysm/dilatation during the followup of patients with giant cell arteritis: a cross-sectional screening of fifty-four prospectively followed patients. Arthritis Rheum 2008:59:422-30.

54 Robson JC, Kiran A, Maskell J, et al. The relative risk of aortic aneurysm in patients with giant cell arteritis compared with the general population of the UK. Ann Rheum Dis 2015;74:129-35.

55 Kermani TA, Warrington KJ, Crowson CS, et al. Large-vessel involvement in giant cell arteritis: a population-based cohort study of the incidence-trends and prognosis. Ann Rheum Dis 2013;72:1989-94.

56 García-Martínez A, Arguis P, Prieto-González S, et al. Prospective long term follow-up of a cohort of patients with giant cell arteritis screened for aortic structural damage (aneurysm or dilatation). Ann Rheum Dis 2014;73:1826-32. 


\section{ARD}

Blocking interferon $\gamma$ reduces expression of chemokines CXCL9, CXCL10 and CXCL11 and decreases macrophage infiltration in ex vivo cultured arteries from patients with giant cell arteritis

Marc Corbera-Bellalta, Ester Planas-Rigol, Ester Lozano, Nekane

Terrades-García, Marco A Alba, Sergio Prieto-González, Ana García-Martínez, Robert Albero, Anna Enjuanes, Georgina

Espígol-Frigolé, José Hernández-Rodríguez, Pascale Roux-Lombard, Walter G Ferlin, Jean-Michel Dayer, Marie H Kosco-Vilbois and Maria C Cid

Ann Rheum Dis 2016 75: 1177-1186 originally published online December 23, 2015

doi: 10.1136/annrheumdis-2015-208371

Updated information and services can be found at:

http://ard.bmj.com/content/75/6/1177

These include: Supplementary
Material

References

Email alerting service
Supplementary material can be found at:

http://ard.bmj.com/content/suppl/2015/12/23/annrheumdis-2015-2083 71.DC1

This article cites 56 articles, 25 of which you can access for free at: http://ard.bmj.com/content/75/6/1177\#BIBL

Receive free email alerts when new articles cite this article. Sign up in the box at the top right corner of the online article.

Topic Articles on similar topics can be found in the following collections Collections

\section{Notes}

To request permissions go to:

http://group.bmj.com/group/rights-licensing/permissions

To order reprints go to:

http://journals.bmj.com/cgi/reprintform

To subscribe to BMJ go to:

http://group.bmj.com/subscribe/ 